\title{
High-risk specialties threatened by runaway legal costs
}

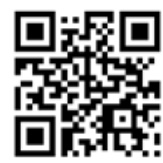

It's hoped that it will take less than a decade, but legal and other reforms urgently needed to address the runaway costs of protecting physicians against clinical negligence which threaten the very existence of higherrisk specialties - now have a starkly clear outline. This emerged after a workshop sponsored by the Medical Protection Society (MPS), in which a review of pertinent global tort reform prompted animated and largely consensual discussion between almost equally represented doctors and lawyers.

The 10 November MPS meeting in Gauteng last year came 8 months after national health minister $\mathrm{Dr}$ Aaron Motsoaledi convened a medicolegal summit to address the explosion of litigation against doctors and hospitals, which is costing the state tens of billions of rands and forcing specialists, most alarmingly obstetricians and gynaecologists, to avoid certain procedures, migrate to less litigious climates, or give up practising altogether. This has prompted expert insiders to predict that if the current trend of obs/gynae specialists leaving the private sector continues for 5 or 6 years, there will be 'no one left to deliver our babies'. Already too thinly spread even to staff the pivotal specialist-led district outreach teams (one of the pillars of the impending National Health Insurance (NHI)), obstetricians and gynaecologists, followed by neurosurgeons, neonatologists and orthopaedic surgeons, pay up to ZAR45 000 per month in MPS subscriptions to avoid potential financial ruin. Data from MPS indicate that between 2009 and 2015 there has been an escalation in the likely value of claims being brought against doctors, with claim sizes increasing by over $14 \%$ on average each year during that period. Their data also indicate that the estimation of the long-term average claim frequency for doctors in 2015 was around $27 \%$ higher than in 2009 .

\section{No drop in professional standards}

The MPS does not believe that the deteriorating claims environment in recent times reflects a deterioration in professional standards, although it does consider that there is scope for standardisation of treatments and processes that could ensure

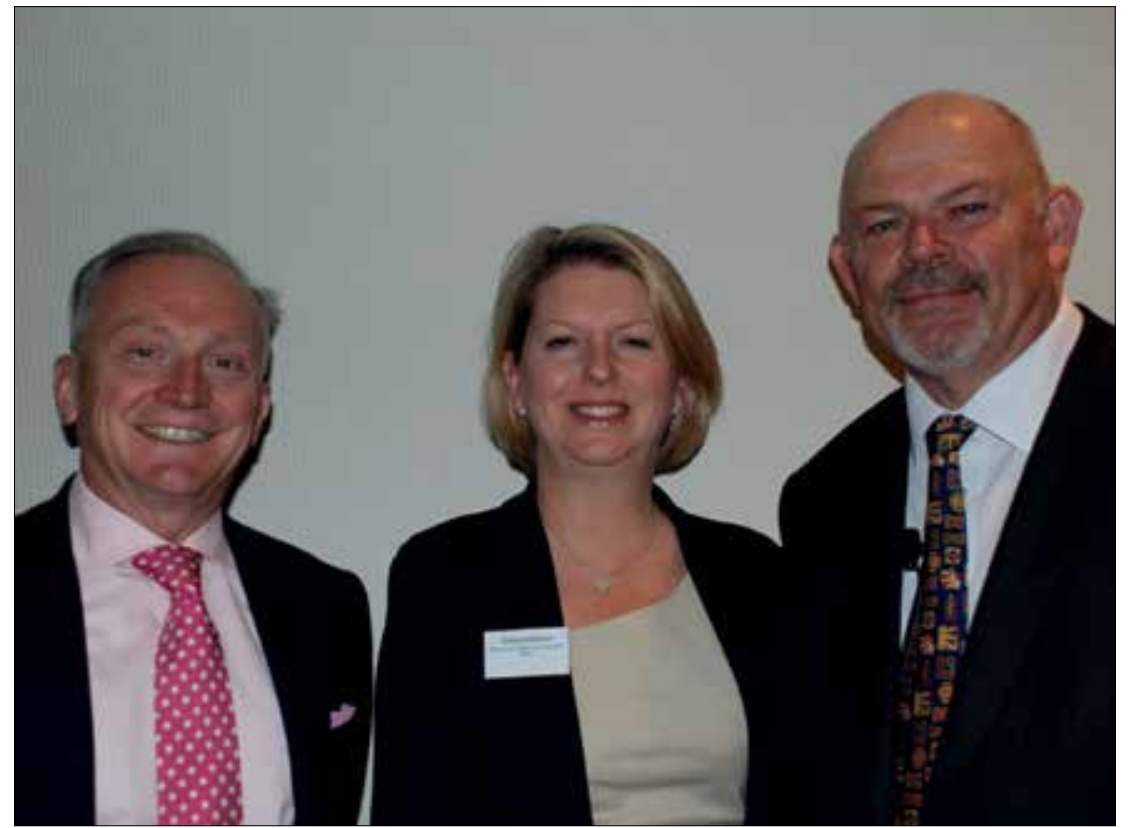

Mark Doepel, an associate professor at the School of Law, University of Notre Dame, Emma Hallinan, MPS Director of Claims, and Dr Graham Howarth, MPS Head of Medicolegal Services for Africa..

a more consistent approach to healthcare. Rather, the litigation climate has changed, with patients more aware and lawyers taking increasing advantage of both environmental factors and the adversarial local model of tort law.

Both Motsoaledi and John Tiernan, Executive Director of the MPS's Member Engagement Division, pointed to the litigation-bankrupted Road Accident Fund as having potentially redirected lawyers' energies at vulnerable healthcare practitioners. The Contingency Fee Act (of 1977) permitting attorneys to offer clients 'free' legal help in pursuing a suit against a medical practitioner $(25 \%$ of the settlement or double their usual fee, whichever is the lesser) is another driver of claims.

Emma Hallinan, MPS Director of Claims and Litigation, told delegates that the current South African (SA) legal framework does not facilitate the efficient and fair resolution of disputes. Damages and costs were soaring and there was no requirement for advance notification of claims and little incentive to reach a solution before proceedings were issued, while the legal system encouraged an adversarial approach that was virtually irreversible once proceedings began. There was also no requirement for clinical experts to meet, and little incentive to exchange expert evidence until shortly before trial. Motsoaledi pulled no punches at his medicolegal summit as to how the current system was being cynically manipulated. He claimed to know of syndicates with members in state hospital managements and various State Attorney's offices respectively tipping off mercenary lawyers and deliberately mismanaging cases to ensure that the state lost. He threatened criminal action against anyone suspected of doing this, adding that a jail term would send out a clear message. Motsoaledi warned that, collectively, his task team, appointed after his 9 March summit, the White Paper on the NHI and the outcome of Chief Justice Mogoeng's enquiry into soaring healthcare costs would 'change the health system as we know it today'.

The MPS's main proposals, based on what has been learnt globally but particularly on Australian legal tort reform, which has left that country with arguably the world's most stable healthcare litigation environment, centre on early expert mediation and filtering out frivolous and/or vexatious claims, which prove hugely costly and time-consuming. Hallinan said that the initial complaints process needed to be 'consistent, efficient, aligned and patient centred', allowing for local resolution. A powerful handbrake would be a certificate of merit requiring the 
complainant's lawyer to sign formal court documents saying that he/she believed the case had a reasonable chance of success, with the inbuilt prospect of court censure including the lawyer paying for both parties' legal fees - should the judge find otherwise. Hallinan said that all other early alternative dispute resolution measures should be considered, including a prelitigation resolution framework. Procedural changes should include an exchange of factual witness statements, an early exchange of expert notices and summaries, and mandatory meetings with experts. The MPS proposes that a tariff of general damages be created in law, including limits on general damages, future care costs and loss of future earnings.

\section{Australia side-steps medicolegal ruin - now a global model}

Mark Doepel, an associate professor at the School of Law, University of Notre Dame, said that ever-increasing damages awards 'almost brought the Australian healthcare system to its knees' before extensive reforms were made about a decade ago. A federal government tort reform committee, headed by an SA-born judge and New South Wales High Court appeal judge, David Ipp, 'completely rewrote' the Australian tort landscape. Adopted were provisions encouraging early apologies and expressions of regret, proportionate liability (paying in ratio to the amount of damage caused), threshold caps, meritorious caps (or certificate of merit), and protection for Good Samaritans (blanket immunity from being sued for anyone, such as an off-duty doctor, acting in good faith during an emergency). Doepel said there were obvious risky recreational activities (such as bungee jumping or swimming in the ocean) for which providers or authorities had been held liable for damages in the past.

'I was recently asked to give an opinion on a cerebral palsy case, and a Down syndrome patient walked through the door - it's not surprising that things go wrong' medical geneticist

He told a 'partly true' story (compiled from real-life case studies) to compare the new world order' with previous legal regimes when it came to tort law and the balancing of rights and personal responsibility. Under Australia's previous tort regime, an Irish backpacker rendered tetraplegic by rough three- to four-metre waves in which he was drunkenly swimming on Bondi Beach in Sydney was awarded 20 million Australian dollars. The backpacker and his Australian mates were drinking beer in a picnic area, and he was last seen walking towards the water. An off-duty medic found him lying face down in the waves, pulled him out and called an ambulance. The backpacker contended that the medic did not use sufficient care by throwing him onto the sand, and submitted that he 'must have' entered the water between the red flags demarcating the 'safe' swimming area.

Doepel told his audience that in today's legal environment the lawyer representing the ill-fated backpacker would first have to ensure that he had a reasonable case. 'I'd say he doesn't. The victim cannot give evidence that he entered the water between the flags, and the doctor was doing his best under the circumstances. Now we'd have to resolve matters in negotiations, and if it gets to court, the scope of duties is prescribed. If you've been drinking there is a significant reduction in damages. Even if he saw the flags, they're only a representation that this is a control area. In today's world he'd probably get nothing.

\section{When teaching can ruin you ...}

A delegate who described himself as an experienced laparoscopic surgeon with a history of very few patient complications said that when he sought out the most respected legal advice in the country, he was told that he would be culpable for any mistakes made by a registrar while he was teaching him or her a practical procedure. 'We want to make surgery safer, but in doing so we're exposing ourselves to risk', he complained. Doepel responded that the surgeon's input had 'a real flavour of fear to it', something he and his international colleagues were very familiar with. 'As South Africans you're trying to do your very best but you're still going to get sued - that's what tort reform will change. It's a fundamental paradigm shift that sets up a tort system with protections. It's not about putting lawyers back in their box. At least two neurosurgeons and a retired judge commented on the 'striking similarity' between Motsoaledi's medicolegal summit and the MPS workshop, urging the MPS to slot in with the health minister's task team in making urgent recommendations to the SA Law Reform Commission. One neurosurgeon said that the MPS should collate data to show 'where we are falling down and why', so that in addition to tort reform the profession could identify what intrinsic common mistakes were being made, and geographically identify their locations. Dr David Bass, legal advisor to the Western Cape Department of Health, said his administration was building in early complaints procedures and mediation capacity (something several other provinces are now slowly following). 'We're trying to introduce an element of disinterest and a non-partisan approach to disputes. Doing this early and promptly can cut down a number of serious cases,' he said.

\section{The estimation of the long-term average claim frequency for doctors in 2015 was around 27\% higher than in 2009.}

Retired Gauteng High Court Judge Neels Claasen said that he wholeheartedly supported the MPS suggestions for tort reform and preventing litigation through early mediation and negotiation. He gave the example of his recently being asked by the National Department of Health to deal with two rural families who suffered 'severe trauma and damage' as a result of clear negligence by staff at two national hospitals. 'We explained to them the benefits of mediation $\mathrm{v}$. the disadvantages of litigation, and they agreed to mediation. Both matters were finalised in a single day, costing almost nothing.' Elaborating, he said one mother of a victim was so traumatised she could not speak, while her jobless husband also initially remained silent. The mediators creatively asked representatives of nearby national hospitals whether they had a job for the man. 'As it turned out, one of their heads of security had just resigned and the hospital said that if our client qualified, he could have the job.' The man was subsequently employed and the bereaved family given a steady income stream. Judge Claasen said that both matters would have taken 2 - 5 years for resolution in court. 'In SA we have demonstrations for lack of service delivery, students protesting that fees must fall and all of it easily erupting into violence. The health crisis is very serious and we need to join forces and work as a block if we are to resolve these issues,' he added.

\section{Come clean, apologise - and live to work another day}

The MPS presenters repeatedly cited cases in which early and genuine expressions of regret to patients by doctors following an adverse event had had a major impact, hugely 
mitigating the outcome. Said Doepel: 'Once the writ is served, strap yourself in - it's almost impossible to parachute out. Early empathy and understanding can make a huge difference.' Lawyers around the world seemed to have forgotten 'who they are and what their obligations are. We are professional advisors. One of the troubling things I see every day is: "I will act because I think there's a buck in it". The certificate of merit [for a case] brings them back to what their obligation is, he added. Medical geneticist Prof. Arnold Christianson said that he was working in a province where litigation had reached ZAR5 billion, adding that it was 'now virtually impossible to do a decent job'. He said some of the claims coming through were 'preposterous'. 'I was recently asked to give an opinion on a cerebral palsy case, and a Down syndrome patient walked through the door - it's not surprising that things go wrong.' He said that provincial governments were now also looking to see if their doctors could be held liable if their Health MECs were found culpable. 'I think you [i.e. the MPS] are limiting yourselves if you're addressing only the private sector - it's a disaster out there.'

Tiernan replied that while the MPS did not indemnify in the public sector, the remedies being suggested were for the entire system, and only South Africans could drive them forward.

Doepel was highly critical of 'no-fault' compensation schemes, saying they would almost certainly fail for financial reasons and had almost bankrupted the New Zealand healthcare system. 'Lawyers hate a vacuum and will re-enliven personal actions. It's like the rental car being the fastest car around. As a philosophical, financial and regulatory mechanism, I'm no great fan of no-fault compensation schemes', he said. Hallinan said that the House of Parliament's Health Committee reported in 2011 that they had heard evidence that the National Health Service bill in the UK would increase by between $20 \%$ and $80 \%$ were a no-fault compensation scheme to be introduced.

\section{Chris Bateman}

chrisb@hmpg.co.za

$S$ Afr Med J 2016;106(1):9-11.

DOI:10.7196/SAMJ.2016.v106i1.10415 
teaching. 'Teachers instil certain qualities of themselves in their students, and his lack of remorse and involvement in apartheid warfare makes students very uncomfortable. They would rather have other tutors', he added. Prof. Marietjie de Villiers, Deputy Dean of Education in the Faculty of Medicine and Health Sciences at Stellenbosch University, described the anomaly as 'a technical difficulty'. 'There's a difference between being appointed and being on the teaching staff, and being accredited as a clinical supervisor,' she explained, adding that Basson had never taught on campus. While Medi-Clinic had been accredited as a 'group', the individuals giving tutorials also had to be named, she confirmed. 'People use the word "taught" loosely', she said. Explaining the 11-month delay in revoking Basson's teaching rights after he was found guilty, she said the process began after the 2013/14 festive season academic break. The unprecedented revocation followed a quality assurance process that began with the MB ChB Programme Committee, moving to the Faculty Undergraduate Committee, to the Faculty Board and finally to the University Senate - all of which had student representation. She conceded that the student representatives at the time would not have been Wayne or any of his current committee.

\section{Initial student silence on Basson's teaching questioned}

Moodley questioned why the student body had allowed Basson to continue tutoring for so long without speaking up. 'Perhaps it is because student protests around the country have empowered and liberated students to freely express their views', she speculated, expressing concern that 'a subset of students had no discomfort with his apartheid-related

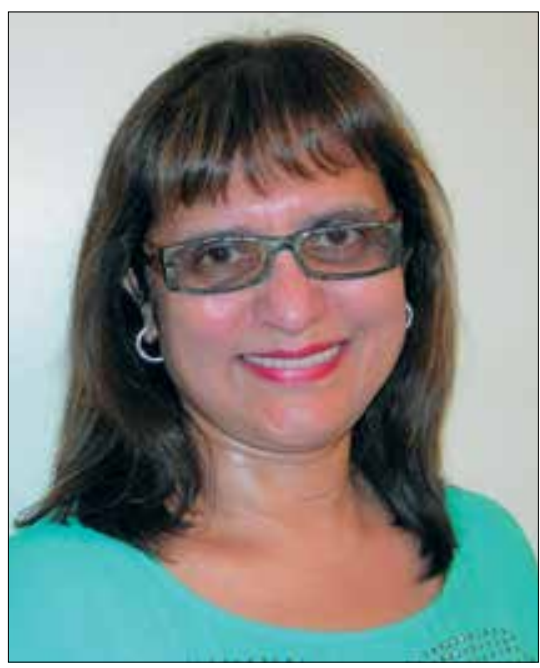

Ex-SAMA President Prof. Ames Dhai. activities that transgressed the foundational principles of the profession and basic respect for human rights'. Yet other students 'showed a profound dialectical capability in sharing the same space with someone they respected as a clinician, yet deplored as a health professional and human being. De Villiers said that there was a well-publicised and regularly used complaints procedure for students, emphasising that there was no complaint on record about Basson's tutelage. Attendance at his tutorials was voluntary, she reaffirmed. Dhai, who is Chairperson of SAMA's Human Rights and Ethics Committee, said: 'It boils down to a question of trust. Clearly, through everything that's happened and what he was convicted of by the HPCSA, there's been a real erosion of integrity on his part. Medical students are in their formative years of study. They learn not only from the formal curriculum but the informal one. Bad habits have been picked up from the hidden curriculum and the behaviour patterns of our teachers. The Remunerative Work outside the Public Service abuse is an excellent example of this. Is he worthy of our trust? In my opinion he's lost people's trust and is not worthy of it, not only because of what he did, but the manner in which he's conducted himself subsequently. His lack of remorse and continuous opposing of Council is absolutely cynical.' Basson said he had 'no idea what the fuss is about. I teach many groups of people and have received no complaints, related to either the giving thereof or the quality thereof, at all over the years, from any of my students. My lectures are a given - the attendees are there of their own volition.' Many doctors and specialists regularly received continuing professional development points by attending his lectures, he added. Moodley challenged the student and lecturer bodies to 'examine the extent to which we idolise and exaggerate the competence of Wouter Basson, perhaps because his worldview of human rights abuses parallels our own worldviews about racism or conversely, what we find reprehensible about him may reflect a poignant sense of injustice induced by the apartheid regime and the institutional culture of some tertiary educational institutions.' She hoped that institutions of higher learning would in future ensure that 'such debate is encouraged contemporaneously and that safe spaces are created for face-to-face discussion, in addition to social media discussions'.

Dr Kgosi Letlape, President of the Health Professions Council of South Africa, said that there were no limitations on Basson's registration with the MDPB. No healthcare practitioner could be restricted in his or her practice until the last legal word had been

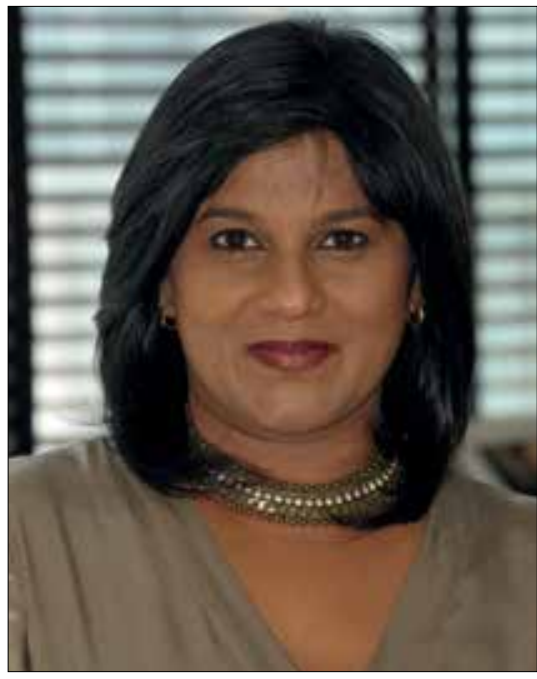

Associate Professor and Head of the Centre for Medical Ethics and Law at Stellenboch University, Prof. Keymanthri Moodley.

spoken. 'He has rights like any other citizen, and the laws of the country still prevail', he stressed.

\section{SAMA Chair: 'don't lean on the private sector'}

SAMA Chairperson Dr Mzukisi Grootboom said he understood what MediClinic was 'trying to drive towards', but disagreed with 'the constant call among the leadership of academic health centres to allow a private practice platform to teach medical students'.

'I don't think it's appropriate. What we need is for these same leaders to advocate for government to do what is correct, and that is to equip and capacitate academic hospitals to cater for and be accessible to the majority of people. The unintended consequence of this [private sector] approach is that it perpetuates the perception that the system has failed. Academic teaching platforms should meet the requirements of teaching medical students. If they allow the situation to deteriorate any further, we won't have a teaching platform.' Focusing on primary healthcare was vital, but not at the expense of tertiary health centres, he added.

Izindaba has learnt that the Tygerberg/ Boland branch of SAMA supported Basson in complaining about the petition against the cardiologist (launched by the People's Health Movement, not SAMA). However, SAMA refused to apologise for supporting the petition, responding that its predecessor (the Medical Association of South Africa, MASA) was a founding member of the World Medical Association, formed in direct response to Nazi atrocities performed by doctors on living human beings. The same 
'covenant', which held that even in times of war no doctor should use their training to kill instead of heal, was abused by MASA when black consciousness leader Steve Biko was murdered in 1977. Basson only recently withdrew his membership of SAMA.

The MDPB found Basson guilty of co-ordinating the large-scale production of illegal psychoactive drugs (including Ecstasy), arming mortars with teargas and providing military operatives with disorientating substances to make illegal cross-border kidnappings easier. $\mathrm{He}$ also made cyanide capsules available to apartheid-era military spies so that they could commit suicide if captured - a slow and painful death, the antithesis of 'quick and painless' James Bond-type spy suicides.
Hugo said in his judgment that medical ethics were 'especially important' in times of war and conflict. Basson had 'defiled the unique and sacred position' of trust in doctors by society that impelled them to stay true to the ethical values of 'beneficence, non-malificence, justice and autonomy'.

South African Military Health Service Surgeon General, Lt.-Gen. A P Sedibe, said that Basson was no longer on their payroll, but declined to answer questions on how long he had been. Head of Communications in the national defence ministry, Siphiwe Dlamani, confirmed that the South African National Defence Force (SANDF) was footing Basson's hefty legal bill, 'by virtue of his having been in the SANDF in the past'. The State is paying both the HPCSA's and Basson's legal bills but no state official will reveal or even estimate what this has cost so far. The professional conduct hearing has dragged on six times longer than the corruption trial of the late former police commissioner, Jackie Selebi (2009 - 2012) - and that cost ZAR17 million. Basson was acquitted in a lengthy criminal trial that predated the current ethics-related hearing. When he will be sentenced remained an open question at the time of writing.

\section{Chris Bateman}

chrisb@hmpg.co.za

$S$ Afr Med J 2016;106(1):11-13.

DOI:10.7196/SAMJ.2016.v106i1.10416

\section{BOOK REVIEW}

\section{Being Mortal - Illness, Medicine, and What Matters in the End}

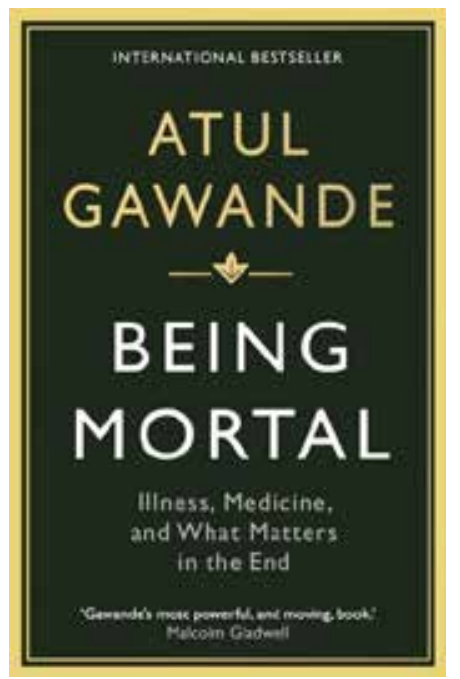

By Atul Gawande. Newton, MA: Wellcome Collection, 2014. ISBN 978-1-84668-582-8

Atul Gawande, a surgeon and professor at Harvard Medical School and a staff writer for the New Yorker, is the author of three previous books focusing on difficult issues doctors face.

In Being Mortal he takes a clear-eyed view of issues that have to be dealt with in an era when many people are living longer, often into debility, and when dying of old age is not a rarity. Gawande uses the stories of patients, friends and family to make important points. Modern medicine is primed to fix even what is unfixable: we mortals fear debility and death. In the attempt to extend life at all costs, unnecessary suffering is inflicted and personal finances and healthcare budgets are crippled. As Gawande says, 'We've been wrong about what our job is in medicine. We think our job is to ensure health and survival. But really it is larger than that. It is to enable well-being.'

In the chapter 'A better life', Gawande discusses interesting studies where using simple measures - three square meals a day, reporting falls, adjusting medications - dramatically reduced the amount of time the elderly spent in hospital, so improving the quality of the last period of their lives. These interventions do not generate the revenue that actively treating patients does. The fields of gerontology and geriatric medicine in the USA are therefore unpopular, underfunded and understaffed.

Several clinical trials have shown that stopping treatment in cancer patients when previous lines of treatment have failed, together with the early institution of palliative care, results in their living a better quality and, more surprisingly, a longer life. That we do not often discuss this with our patients shows what happens when we confuse care with treatment.

The chapter titled 'Hard conversations' cuts to the heart of this. Here Gawande deals with those candid discussions that are difficult for both patient and caregiver but crucial to ensuring that illusions are removed and achievable goals are looked at realistically and compassionately. Excellent pointers are given in negotiating this crucial interaction.

Patient priorities are more than prolonging life and include avoiding suffering, mental alertness, improving relationships with family and friends, not being a burden, and feeling that their lives have not been a waste of time. 'Endings matter', says Gawande. The current system of high-tech medical care is failing our patients in meeting these needs, and the cost of this failure is enormous, financially and also in causing unnecessary suffering.

He movingly charts his own journey from being an 'informative' to an 'interpretive' doctor: from one who merely enumerates treatment options, often when this risks doing harm with little hope of benefit, to one who assists patients in managing the latter stages of their lives in a way that is meaningful to them. This interpretive approach requires spending the time to learn what the patient's goals are, understanding what risks and trade-offs they are prepared to accept in exchange for their independence, comfort and dignity, and then assisting them in realising this.

In the last chapter, titled 'Courage', Gawande looks at our personal responsibility in planning ahead for our inevitable ageing and death. It takes courage to confront this reality and to act on it. The reality is that if we do not do it, it will be left to others to take those decisions on our behalf, and with that the last vestige of our independence. It is up to us to ensure that our last days are more comfortable and meaningful. As this thought-provoking book shows, it is our dignity and humanity that matter in the end.

\section{David Eedes}

Clinical oncologist, Three Anchor Bay, Cape Town

daveed@mweb.co.za 